REVIEW

\title{
Prática gerencial do enfermeiro no ambiente hospitalar
}

\author{
Bruno Alax Arruda do Lago ${ }^{a}$, Aline Sharlon Maciel Batista Ramos ${ }^{b}$ (D), Kardene Pereira Rodrigues ${ }^{c}$ \\ , Débora Luana Ribeiro Pessoad ${ }^{d}$
}

\begin{abstract}
aEnfermeiro, especialista em Gestão em Saúde, Universidade Estadual do Maranhão (UEMA), MA, Brasil.
bEnfermeira, docente da Universidade Ceuma. Rua Josué Montello, № 1, Renascença II, 65.075-120. São Luís, MA, Brasil.

'Enfermeira, docente da Faculdade Gianna Beretta. Av. Jerônimo de Albuquerque, 1100 - Bequimão, 65060-645, São Luís, MA, Brasil.
\end{abstract}

${ }^{d}$ Farmacêutica, docente da Universidade Federal do Maranhão (UFMA), Estrada de Pacas, S/N, Enseada, Pinheiro, MA, Brasil.

RESUMO Este trabalho busca apresentar a importância da ação gerencial do enfermeiro no ambiente hospitalar. Foi realizado um trabalho de revisão integrativo, que possibilita a interpretação do conteúdo encontrado. Utilizou-se como base de dados as plataformas Scielo e Google Acadêmico, e os descritores: "enfermagem", "gerência" e "gerência de enfermagem". Os resultados indicam que é de extrema importância a presença do enfermeiro gerente no meio hospitalar, pois promove uma intervenção mais efetiva na realidade de saúde do paciente através do processo educativo e contínuo dos liderados, trabalho e em um contexto geral, o qual engloba de uma vez só, serviços, materiais, métodos e assistência direta. Percebe-se ainda que há a necessidade do desenvolvimento de mais trabalhos na área.

PALAVRAS-CHAVE: enfermagem; gerência; gerência de enfermagem

Recebido 21 de janeiro de 2019 Aceito 27 de janeiro de 2019 Publicado online 17 de abril de 2019

Cite este artigo: Lago BAA et al. (2019) Prática gerencial do enfermeiro no ambiente hospitalar. Multidisciplinary Reviews 2: e2019002, DOI: 10.29327/multi.2019002

\section{Management practice of nurses in the hospital environment}

ABSTRACT This paper seeks to present the importance of the managerial action of nurses in the hospital environment. An integrative revision work was carried out, which allows the interpretation of the content found. The Scielo and Google Scholar platforms were used as the database, and the descriptors: "nursing", "management" and "nursing management" were used. The results indicate that it is extremely important the presence of the nurse manager in the hospital environment, since it promotes a more effective intervention in the health of the patient through the educative and continuous process of the ones led, work and in a general context, which includes services, materials, methods and direct assistance. It is also noticed that there is a need to develop more work in the area.

KEYWORDS: nursing; management; nursing management

\section{Introdução}

O trabalho do enfermeiro no contexto hospitalar é amplo e com dimensões múltiplas tendo como objetivo o cliente a quem se presta os cuidados podendo este ser direto ou indireto (Nascimento 2013).

Dos trabalhos desenvolvidos na área da saúde, o da enfermagem difere-se de outras áreas de prestação de serviços, principalmente no contexto hospitalar. A enfermagem tem sua prática relacionada ao atendimento das necessidades expressas por indivíduos ou grupos sociais, demonstradas com a necessidade ou problemas relacionados ao processo saúde-doença. Contudo, atualmente tem-se observado uma crescente demanda de serviços administrativos e gerenciais desenvolvidos por estes profissionais, serviços estes que vem a servir de instrumento indireto na prática do cuidado (Manenti 2008).

Nesta conjuntura administrativa podemos observar as seguintes definições adotadas por Fayol: administrar é prever, organizar, comandar, coordenar e controlar. Prever é perscrutar o futuro e traçar o programa de ação. Organizar 
é constituir o duplo organismo, material e social da empresa. Comandar é dirigir o pessoal. Coordenar é ligar, unir e harmonizar todos os atos e todos os reforços. Controlar é velar para que tudo corra de acordo com as regras estabelecidas (Kurcgant 1991).

A função administrativa no nível intermediário das instituições (departamentos e serviços) recebe a denominação de gerência e se incumbe de conduzir as pessoas para o alcance dos objetivos institucionais. É uma atividade voltada para as pessoas e se fundamenta na motivação, na liderança e na comunicação (Chiavenato 2000).

O gerenciamento de enfermagem engloba desde o cuidado direto ao cliente internado quanto suas ações inerentes à assistência indireta. A heterogeneidade da prática de enfermagem demonstra as múltiplas faces de sua dimensão gerencial (Peduzzi e Husmann 2005).

O serviço gerencial administrativo é de suma importância para o desenvolvimento de qualquer prática trabalhista, inclusive a da enfermagem, uma vez que, como todo processo de trabalho, é regido pelas rudimentares e modernas teorias administrativas, as quais marcaram as cinco primeiras décadas do século passado e ainda podem ser observadas em muitas organizações, influenciando o processo de trabalho (Maximiano 2000).

Nessa perspectiva, busca-se verificar a importância da gerencia de enfermagem nas comissões internas e departamentos hospitalares, com o intuito de conhecer à luz da literatura vigente a presença dessa atividade nas funções do enfermeiro.

A enfermagem, diferente de outras profissões da área da saúde, sempre andou de mãos dadas com a administração, cobrando do enfermeiro em qualquer uma das áreas de atuação, quer seja esferas públicas ou privadas, nas unidades hospitalares ou outras, o papel gerencial.

A principal finalidade desse trabalho foi de conhecer presença do papel gerencial dos enfermeiros nas unidades hospitalares à luz da literatura nacional, e valorizando a presença da enfermagem nas unidades hospitalares na prestação a assistência gerencial.

\section{Materiais e Métodos}

Esse estudo é caracterizado de uma revisão integrativa da literatura referente a gerencia de enfermagem nos setores internos das unidades hospitalares. Ao se realizar a pesquisa pretendeu-se listar os principais estudos publicados neste campo de interesse, buscando-se assim nesse sentido, um método de pesquisa que viabiliza a análise de pesquisas científicas de um modo sistemático (Freitas et al 2013).

A questão norteadora utilizada na proposta para o estudo foi a seguinte: Quais trabalhos publicados nos periódicos on-line, em língua portuguesa, dos anos 2000 a 2015, estão relacionados à gerencia de enfermagem no ambiente hospitalar? Para identificar os estudos publicados sobre essa questão de interesse foi realizada uma busca on-line em periódicos na área de concentração da Enfermagem com indexação nacional, por meio das bases de dados Google Acadêmico e Scientific Eletronic Library Online (SciELO), utilizando-se seguintes descritores: "enfermagem", "gerência" e "gerência de enfermagem". O estudo foi constituído por 10 publicações pertinentes à temática envolvida disponibilizada nos periódicos citados nas bases de dados acima.

Foram utilizados como critérios de inclusão na amostra: estudos realizados por pesquisadores da Enfermagem brasileira disponíveis nas bases de dados selecionadas para a pesquisa proposta; estudos relacionados com a gerência de enfermagem nas unidades hospitalares; estudos disponibilizados na íntegra; estudos publicados no período entre 2000 e 2015; estudos publicados na modalidade artigo científico versões originais ou revisões.

\section{Resultados e Discussão}

A investigação foi realizada pelas produções cientificas relacionada a gerência de enfermagem nos hospitais. Considerando a distribuição dos artigos por ano de publicação, em 2006 tem-se 04 (quatro) publicações, no ano de 2009 02 (duas) e em 2008, 2010, 2012 e 2013, 01 (uma) pesquisa cada. Já sobre os periódicos das publicações utilizadas, a Escola de Enfermagem Ana Nery, Cogitare Enfermagem e Texto \& Contexto de enfermagem com 02 (duas) publicações utilizadas, e as demais, Revista Brasileira de Enfermagem, Revista da Escola de Enfermagem da Universidade de São 
Paulo e Ciência \& Cuidado em Saúde, cada com 01 (uma) publicação. O quadro 1 apresenta a descrição dos autores, base de dados, periódicos e ano de publicação, e o quadro 2 mostra uma síntese dos artigos analisados neste estudo.

Quadro 1 Descrição dos autores, base de dados, periódicos e ano de publicação.

\begin{tabular}{|c|c|c|c|c|c|}
\hline $\mathbf{N}^{\circ}$ & Autores & Base de dados & Título do artigo & Periódico & Ano \\
\hline 01 & $\begin{array}{l}\text { Erdmann AL, Leite JL, } \\
\text { Santos JLG, Prochnow } \\
\text { AG, Silva DC, Silva RM }\end{array}$ & $\begin{array}{l}\text { Google } \\
\text { acadêmico }\end{array}$ & $\begin{array}{l}\text { Prazer e sofrimento no exercício } \\
\text { gerencial do Enfermeiro no contexto } \\
\text { hospitalar }\end{array}$ & $\begin{array}{l}\text { Escola de Enfermagem } \\
\text { Anna Nery }\end{array}$ & 2013 \\
\hline 02 & $\begin{array}{l}\text { Bernardino E, Felli VE, } \\
\text { Peres AM }\end{array}$ & $\begin{array}{l}\text { Google } \\
\text { Acadêmico }\end{array}$ & $\begin{array}{l}\text { Competências gerais para o } \\
\text { gerenciamento em enfermagem de } \\
\text { hospitais }\end{array}$ & Cogitare Enfermagem & 2010 \\
\hline 03 & $\begin{array}{l}\text { Hausmann M, Peduzzi, } \\
\text { M }\end{array}$ & $\begin{array}{l}\text { Google } \\
\text { Acadêmico }\end{array}$ & $\begin{array}{l}\text { Articulação entre as dimensões gerencial } \\
\text { e assistencial do processo de trabalho do } \\
\text { enfermeiro }\end{array}$ & $\begin{array}{l}\text { Texto \& Contexto de } \\
\text { Enfermagem }\end{array}$ & 2009 \\
\hline 04 & $\begin{array}{l}\text { Pompeu B, Sanches VF, } \\
\text { Silvino CZR }\end{array}$ & $\begin{array}{l}\text { Google } \\
\text { Acadêmico }\end{array}$ & $\begin{array}{l}\text { Processo de trabalho do gerente de } \\
\text { enfermagem em unidade hospitalar - } \\
\text { uma visão dos enfermeiros }\end{array}$ & $\begin{array}{l}\text { Escola de Enfermagem } \\
\text { Anna Nery }\end{array}$ & 2006 \\
\hline 05 & $\begin{array}{l}\text { Peres AM, Ciampone } \\
\text { MHT }\end{array}$ & Scielo & $\begin{array}{l}\text { Gerência e competências gerais do } \\
\text { enfermeiro }\end{array}$ & $\begin{array}{l}\text { Texto \& Contexto } \\
\text { Enfermagem }\end{array}$ & 2006 \\
\hline 06 & Soares E, Souza FM & $\begin{array}{l}\text { Google } \\
\text { Acadêmico }\end{array}$ & $\begin{array}{l}\text { Visão administrativa do enfermeiro no } \\
\text { macrossistema hospitalar: um estudo } \\
\text { reflexivo }\end{array}$ & $\begin{array}{l}\text { Revista Brasileira de } \\
\text { Enfermagem }\end{array}$ & 2006 \\
\hline 07 & Chaves LDP, Massaro M & $\begin{array}{l}\text { Google } \\
\text { Acadêmico }\end{array}$ & $\begin{array}{l}\text { A produção científica sobre } \\
\text { Gerenciamento em enfermagem } \\
\text { Hospitalar: uma pesquisa bibliográfica }\end{array}$ & Cogitare Enfermagem & 2009 \\
\hline 08 & $\begin{array}{l}\text { Ciampone MHT, } \\
\text { Manent SA, Minam LF, } \\
\text { Mira VL, Soares JMS }\end{array}$ & Scielo & $\begin{array}{l}\text { O processo de construção do perfil de } \\
\text { competências gerenciais para } \\
\text { enfermeiros coordenadores de área } \\
\text { hospitalar }\end{array}$ & $\begin{array}{l}\text { Revista da Escola de } \\
\text { Enfermagem da } \\
\text { Universidade de São } \\
\text { Paulo }\end{array}$ & 2012 \\
\hline 09 & $\begin{array}{l}\text { Backes DS, Backes MS, } \\
\text { Erdmann AL, Sousa } \\
\text { FGM }\end{array}$ & Scielo & $\begin{array}{l}\text { O papel do enfermeiro no contexto } \\
\text { hospitalar: a visão de profissionais de } \\
\text { saúde }\end{array}$ & $\begin{array}{l}\text { Ciência \& Cuidado em } \\
\text { Saúde }\end{array}$ & 2008 \\
\hline 10 & $\begin{array}{l}\text { Castro CB, Oliveira } \\
\text { SEM, Santos I }\end{array}$ & Scielo & $\begin{array}{l}\text { Gerência do processo de trabalho em } \\
\text { enfermagem: liderança da enfermeira em } \\
\text { unidades hospitalares }\end{array}$ & $\begin{array}{l}\text { Texto \& Contexto } \\
\text { Enfermagem } \\
\text { Florianópolis }\end{array}$ & 2006 \\
\hline
\end{tabular}

Uma observação importante sobre a gerencia de enfermagem foi o encontro, dentre as pesquisas realizadas a de apresentar na atuação gerencial do enfermeiro, de novas formas de competências e um pensamento inovador, levando-se em conta os artigos dos autores Bernardino et al (2010) e Castro et al (2006).

Da mesma forma Pompe et al (2006) aborda a enfermagem, no seu papel de gerencia de enfermagem no ambiente hospitalar, desenvolvido por conceitos empíricos, desenvolvendo-se a partir do aprendizado dia após dia.

Além do papel de gerencia de pessoas, os autores Hausmann e Peduzzi (2009) e Soares e Souza (2006) promovem esse papel gerencial também para os materiais hospitalares e na atividade de controle de qualidade da assistência.

Os valores administrativos, o prazer e o sofrimento, e os conflitos que acontecem quando se desenvolvem esse papel administrativo também é relatado em alguns dos artigos, mais especificamente nas produções cientificas dos autores Erdmann et al (2013), Peres e Ciampone (2006), Ciampone et al (2012), e Backes et al (2008), percebendo-se que além dos problemas administrativos, a questão pessoal acaba contando, e reflete também na assistência, como problemas com a equipe ou até conflitos internos.

E por último, Chaves e Massaro (2009) refere que deve existir investimento para pesquisas sobre o assunto, para que possamos conhecer a realidade do problema, encontrar as possíveis dificuldades e a partir delas, sanar o que possa impedir o bom desenvolvimento da atividade de gerencia na enfermagem. 
Quadro 2 Títulos dos artigo, objetivos, resultados e sínteses das conclusões.

\begin{tabular}{|c|c|c|c|c|}
\hline $\mathbf{N}^{\circ}$ & Título & Objetivos & Resultados & Síntese das conclusões \\
\hline 01 & $\begin{array}{l}\text { Prazer e } \\
\text { sofrimento no } \\
\text { exercício } \\
\text { gerencial do } \\
\text { Enfermeiro no } \\
\text { contexto } \\
\text { hospitalar }\end{array}$ & $\begin{array}{l}\text { Este estudo objetivou } \\
\text { analisar os fatores de } \\
\text { prazer e sofrimento } \\
\text { no exercício gerencial } \\
\text { do enfermeiro no } \\
\text { contexto hospitalar. }\end{array}$ & $\begin{array}{l}\text { Para exercer a atividade gerencial de } \\
\text { tal forma que ela seja fonte de prazer } \\
\text { e saúde, é necessário que o } \\
\text { enfermeiro receba o reconhecimento } \\
\text { pelo trabalho realizado e que a } \\
\text { instituição mobilize esforços para } \\
\text { incentivar a corresponsabilidade nas } \\
\text { atividades gerenciais. }\end{array}$ & $\begin{array}{l}\text { O prazer e sofrimento não podem } \\
\text { ser considerados polos } \\
\text { diametralmente opostos, portanto, } \\
\text { é necessário que os enfermeiros } \\
\text { aprendam a conviver e aceitar essa } \\
\text { dualidade, ambiguidade e } \\
\text { complementaridade, que é inerente } \\
\text { à prática gerencial. }\end{array}$ \\
\hline 02 & $\begin{array}{l}\text { Competências } \\
\text { gerais para o } \\
\text { gerenciamento } \\
\text { em } \\
\text { enfermagem de } \\
\text { hospitais }\end{array}$ & $\begin{array}{lr}\begin{array}{lr}\text { Faz uma reflexão } \\
\text { sobre }\end{array} & \text { as } \\
\text { competências } & \text { gerais } \\
\text { necessárias } & \text { ao } \\
\text { gerenciamento } & \text { em } \\
\text { enfermagem } & \\
\begin{array}{lr}\text { considerando } \\
\text { mudanças }\end{array} & \text { as } \\
\text { tecnológicas } & \text { e } \\
\text { gerenciais. } & \end{array}$ & $\begin{array}{l}\text { As mudanças no processo de trabalho } \\
\text { da enfermeira no hospital foram } \\
\text { ocasionadas por uma sucessão de } \\
\text { eventos: o modelo assistencial } \\
\text { influenciou ou impulsionou a adoção } \\
\text { de novos modelos gerenciais, que, por } \\
\text { sua vez, demandaram outros perfis no } \\
\text { cuidado, no gerenciamento, nas } \\
\text { relações e na posição política. }\end{array}$ & $\begin{array}{l}\text { A imposição de novos perfis } \\
\text { profissionais demanda a aquisição } \\
\text { de competências, que considera os } \\
\text { conhecimentos acumulados, } \\
\text { moldados em uma perspectiva } \\
\text { dinâmica, com potencial adaptativo. } \\
\text { É possível a construção de } \\
\text { competências, que surgem a partir } \\
\text { de uma necessidade concreta, pelo } \\
\text { aprendizado em situações de } \\
\text { mobilização de conhecimentos, } \\
\text { desde que sejam acompanhadas de } \\
\text { uma reflexão crítica. }\end{array}$ \\
\hline 03 & $\begin{array}{l}\text { Articulação } \\
\text { entre as } \\
\text { dimensões } \\
\text { gerencial e } \\
\text { assistencial do } \\
\text { processo de } \\
\text { trabalho do } \\
\text { enfermeiro }\end{array}$ & $\begin{array}{lr}\text { Estudo com } \\
\text { objetivo de analisar a } \\
\text { dimensão gerencial } \\
\text { do processo de } \\
\text { trabalho } & \text { do } \\
\text { enfermeiro } & \text { para } \\
\text { identificar } & \text { e } \\
\text { compreender } & \text { as } \\
\text { possíveis articulações } \\
\text { com a dimensão } \\
\text { assistencial }\end{array}$ & $\begin{array}{l}\text { A visão dos enfermeiros que estão } \\
\text { participando das mudanças } \\
\text { organizacionais, essencialmente } \\
\text { administrativas, centradas na revisão } \\
\text { de processos, economia e controle, a } \\
\text { melhoria que ocorre na assistência de } \\
\text { enfermagem não é planejada com } \\
\text { foco no cuidado ao cliente, e sim } \\
\text { como decorrência da revisão de } \\
\text { processos e da necessidade de } \\
\text { manter o cliente, principalmente o de } \\
\text { convênios, porque ele é a garantia da } \\
\text { sobrevivência das organizações. }\end{array}$ & $\begin{array}{l}\text { A investigação mostra que } \\
\text { predomina atividades de } \\
\text { gerenciamento de materiais, } \\
\text { controle de equipamentos, custo e } \\
\text { escala de pessoal, o que permite } \\
\text { observar o exercício de um modelo } \\
\text { tradicional de gerenciamento, com } \\
\text { escasso espaço de interação entre } \\
\text { enfermeiro e equipe de } \\
\text { enfermagem e, investimento em } \\
\text { ações educativas de trabalhadores } \\
\text { que estimulem a reflexão sobre o } \\
\text { cotidiano de trabalho. Essa prática } \\
\text { da dimensão gerencial convive com } \\
\text { uma concepção incipiente de } \\
\text { gerenciamento do cuidado. }\end{array}$ \\
\hline 04 & $\begin{array}{l}\text { Processo de } \\
\text { trabalho do } \\
\text { gerente de } \\
\text { enfermagem } \\
\text { em unidade } \\
\text { hospitalar - } \\
\text { uma visão dos } \\
\text { enfermeiros }\end{array}$ & $\begin{array}{l}\text { Nesta pesquisa } \\
\text { delimitamos como } \\
\text { objeto de estudo a } \\
\text { visão do enfermeiro } \\
\text { quanto ao processo } \\
\text { de trabalho do } \\
\text { gerente de } \\
\text { enfermagem }\end{array}$ & $\begin{array}{l}\text { São enfatizadas a supervisão e a } \\
\text { coordenação como partes } \\
\text { importantes do processo de trabalho } \\
\text { do gerente, pois a supervisão é um } \\
\text { processo educativo e contínuo, que } \\
\text { consiste, fundamentalmente, em } \\
\text { motivar e orientar os supervisionados } \\
\text { na execução das atividades com base } \\
\text { em normas, a fim de manter elevada } \\
\text { a qualidade dos serviços prestados }\end{array}$ & $\begin{array}{l}\text { As enfermeiras possuem } \\
\text { conhecimento sobre a } \\
\text { administração em enfermagem, } \\
\text { apesar de seus conceitos não serem } \\
\text { baseados formalmente em teorias } \\
\text { administrativas. }\end{array}$ \\
\hline 05 & $\begin{array}{l}\text { Gerência e } \\
\text { competências } \\
\text { gerais do } \\
\text { enfermeiro }\end{array}$ & $\begin{array}{l}\text { O presente artigo } \\
\text { busca descrevê-las e } \\
\text { relacionar os } \\
\text { conhecimentos } \\
\text { necessários para a } \\
\text { formação dessas } \\
\text { competências }\end{array}$ & $\begin{array}{llr}\text { Para o desenvolvimento da } & \text { de } \\
\text { competência administração } & \text { e } \\
\text { gerenciamento são considerados } \\
\text { indispensáveis o conjunto de } \\
\text { conhecimentos identificados para } \\
\text { planejar, tomar decisões, interagir, } \\
\text { gestão de pessoal. }\end{array}$ & $\begin{array}{l}\text { A modalidade de formação por } \\
\text { competências deve ser analisada } \\
\text { para não refletir apenas mais um } \\
\text { modismo que serve a interesses de } \\
\text { grupos específicos tanto do ensino, } \\
\text { quanto do mercado de trabalho. }\end{array}$ \\
\hline
\end{tabular}




\begin{tabular}{|c|c|c|c|c|}
\hline 06 & $\begin{array}{l}\text { Visão } \\
\text { administrativa } \\
\text { do enfermeiro } \\
\text { no } \\
\text { macrossistema } \\
\text { hospitalar: um } \\
\text { estudo } \\
\text { reflexivo }\end{array}$ & 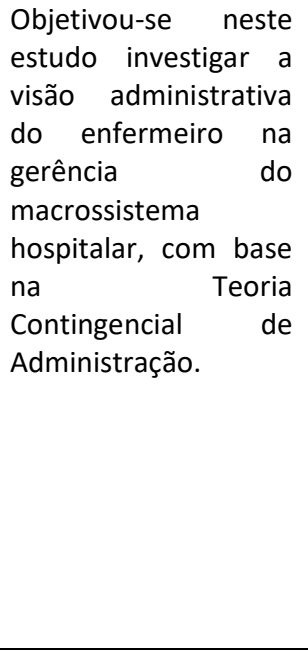 & $\begin{array}{l}\text { Mediante a busca de novos modelos } \\
\text { de administração que possam } \\
\text { aproximar mais a enfermagem do seu } \\
\text { real papel profissional, criando } \\
\text { condições, assim, para uma } \\
\text { intervenção mais efetiva na realidade, } \\
\text { e prestando, por conseguinte, uma } \\
\text { assistência de boa qualidade em } \\
\text { todos os níveis de atenção. }\end{array}$ & $\begin{array}{l}\text { Na visão administrativa do } \\
\text { enfermeiro no Marcossistema } \\
\text { Hospitalar, observou-se uma } \\
\text { tendência associativa do exercício } \\
\text { de gerência para as atividades de } \\
\text { liderança e de controle. Nessa } \\
\text { circunstância, apesar dos } \\
\text { profissionais de enfermagem terem } \\
\text { essa visão clara e determinada de } \\
\text { sua função administrativa no } \\
\text { processo de trabalho, entendida } \\
\text { como atividade de liderança e de } \\
\text { controle, ainda persistem certos } \\
\text { comportamentos que se } \\
\text { contrapõem à realidade, refletindo } \\
\text { contradições que existem no seu } \\
\text { cotidiano. }\end{array}$ \\
\hline 07 & $\begin{array}{l}\text { A produção } \\
\text { científica sobre } \\
\text { Gerenciamento } \\
\text { em } \\
\text { enfermagem } \\
\text { Hospitalar: uma } \\
\text { pesquisa } \\
\text { bibliográfica }\end{array}$ & $\begin{array}{l}\text { Pesquisa bibliográfica } \\
\text { com objetivo de } \\
\text { identificar e analisar a } \\
\text { produção científica } \\
\text { sobre gerenciamento } \\
\text { em enfermagem, em } \\
\text { hospitais, no Sistema } \\
\text { Único de Saúde, no } \\
\text { período de 1988- } \\
2007 \text {. }\end{array}$ & $\begin{array}{l}\text { A dicotomia entre o método de } \\
\text { trabalho de enfermagem e sua } \\
\text { filosofia gera polaridade, entre a visão } \\
\text { holística do homem e a divisão do } \\
\text { trabalho em tarefas; o pensar e o } \\
\text { fazer; a administração rigidamente } \\
\text { hierarquizada e a concepção moderna } \\
\text { de gerenciamento; a produtividade e } \\
\text { a qualidade da assistência de } \\
\text { enfermagem. }\end{array}$ & $\begin{array}{l}\text { Esta revisão bibliográfica evidenciou } \\
\text { que o gerenciamento de } \\
\text { enfermagem em hospitais no } \\
\text { âmbito, do Sistema Único de Saúde, } \\
\text { constitui-se uma lacuna que requer } \\
\text { um investimento na produção de } \\
\text { conhecimentos nesta área tão } \\
\text { significativa para a enfermagem } \\
\text { brasileira. }\end{array}$ \\
\hline 08 & $\begin{array}{l}\text { O processo de } \\
\text { construção do } \\
\text { perfil de } \\
\text { competências } \\
\text { gerenciais para } \\
\text { enfermeiros } \\
\text { coordenadores } \\
\text { de área } \\
\text { hospitalar }\end{array}$ & $\begin{array}{l}\text { Este estudo objetivou } \\
\text { construir o perfil de } \\
\text { competências } \\
\text { gerenciais, } \\
\text { consensuado por } \\
\text { enfermeiros } \\
\text { coordenadores de } \\
\text { área. }\end{array}$ & $\begin{array}{l}\text { Acúmulo de atribuições, que somados } \\
\text { à falta de recursos humanos } \\
\text { suficientes para prestar a assistência } \\
\text { almejada, culmina no } \\
\text { comprometimento direto dos } \\
\text { resultados dos trabalhos assistencial e } \\
\text { gerencial. }\end{array}$ & $\begin{array}{l}\text { Conclui-se que a construção } \\
\text { consensuada do perfil de } \\
\text { competências gerenciais impacta, } \\
\text { de modo positivo, no } \\
\text { direcionamento das atividades de } \\
\text { recrutamento, seleção e } \\
\text { desenvolvimento de pessoal } \\
\text { realizado pelo Serviço de Educação } \\
\text { Continuada (SEC), bem como } \\
\text { contribui na produção de } \\
\text { conhecimento no âmbito do } \\
\text { processo de trabalho gerencial do } \\
\text { enfermeiro em serviços distintos. }\end{array}$ \\
\hline 09 & $\begin{array}{l}\text { O papel do } \\
\text { enfermeiro no } \\
\text { contexto } \\
\text { hospitalar: a } \\
\text { visão de } \\
\text { profissionais de } \\
\text { saúde }\end{array}$ & $\begin{array}{l}\text { Analisar } \\
\text { concepções acerca do } \\
\text { trabalho do } \\
\text { enfermeiro no } \\
\text { contexto hospitalar } \\
\text { sob o olhar da equipe } \\
\text { multiprofissional da } \\
\text { saúde. }\end{array}$ & $\begin{array}{l}\text { Além do fazer e/ou executar rotineiro, } \\
\text { é preciso que o enfermeiro reflita } \\
\text { sobre a sua prática profissional, para } \\
\text { que esta não se torne uma ação } \\
\text { mecanizada, desprovida de vida e } \\
\text { sentido. O fazer pelo fazer desmotiva } \\
\text { e desestimula e, com o tempo, } \\
\text { favorece o comodismo e a } \\
\text { acomodação profissional. }\end{array}$ & $\begin{array}{l}\text { A atuação do enfermeiro, sob o } \\
\text { olhar da equipe da saúde, revela-se } \\
\text { a partir de dicotomias e conflitos, } \\
\text { de modo que o enfermeiro } \\
\text { desempenha papel importante nas } \\
\text { relações da equipe de saúde. }\end{array}$ \\
\hline 10 & $\begin{array}{l}\text { Gerência do } \\
\text { processo de } \\
\text { trabalho em } \\
\text { enfermagem: } \\
\text { liderança da } \\
\text { enfermeira em } \\
\text { unidades } \\
\text { hospitalares }\end{array}$ & $\begin{array}{l}\text { Para identificar } \\
\text { formas de liderança } \\
\text { analisou-se a } \\
\text { dimensão imaginativa } \\
\text { da equipe de } \\
\text { enfermagem sobre o } \\
\text { comportamento de } \\
\text { gerencial no seu } \\
\text { enfermeiras no } \\
\text { cotidiano de trabalho. }\end{array}$ & $\begin{array}{l}\text { Para enfrentar problemas da gerência } \\
\text { em enfermagem, as enfermeiras } \\
\text { devem desenvolver uma liderança } \\
\text { dialógica e libertadora, gerenciando o } \\
\text { cuidar em enfermagem, mediante um } \\
\text { processo educativo e contínuo } \\
\text { visando o incentivo e a orientação dos } \\
\text { liderados na execução de suas } \\
\text { atividades. }\end{array}$ & 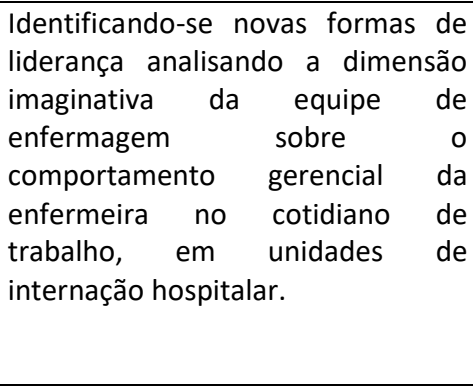 \\
\hline
\end{tabular}




\section{Considerações finais}

Pode-se observar que mesmo com todas as dificuldades, como a tendência própria da profissão em atuar na assistência direta, o papel gerencial da enfermagem é de suma importância no contexto intra-hospitalar, uma vez que a inovação constante das atividades de enfermagem bem como o aprendizado prático da liderança para resolução de problemas, promovem uma intervenção mais efetiva na realidade do paciente em um contexto geral, o qual englobam de uma vez só serviços, materiais, métodos e assistência direta.

Sendo assim, o papel da gerência de enfermagem deve sim existir e cada vez mais ser fomentado pelas gerências maiores, uma vez que através dela ocorre o processo educativo e contínuo dos liderados, no caso, a maior parte dos colaboradores do meio hospitalar, os quais deverão estar sempre motivados para a realização das tarefas diárias.

É preciso também investir em pesquisas neste âmbito para a posterior demonstração científica da importância de tal gerencia neste contexto.

\section{Referências}

Brasil, Ministério da Educação, Conselho Nacional de Educação (2001). Resolução CNE/CES № 3, de 7 de novembro de 2001. Institui Diretrizes Curriculares Nacionais do Curso de Graduação em Enfermagem. Acesso em 23 de maio de 2011. Disponível em:http://portal.mec.gov.br/cne/arquivos/pdf/CES03.pdf. Acesso em 20 nov 2015.

Backes DS, Backes MS, Sousa FGM, Erdamann AL (2008) O papel do enfermeiro no contexto hospitalar: a visão de profissionais de saúde. Ciência e Cuidado em Saúde 7:319-326.

Barreto VPM (2009) Gerência do cuidado prestado pelo enfermeiro a clientes internados em terapia intensiva. Dissertação (Mestrado em Enfermagem) - Universidade Federal do Estado do Rio de Janeiro, Rio de Janeiro. Disponivel em: www.objnursing.uff.br/index.php/nursing/article Acesso em 19 nov 2015.

Bernadino E, Felli VE, Peres AM (2010) Competências gerais para o gerenciamento em enfermagem de hospitais. Cogitare Enfermagem 2:349-353.

Castro CB, Oliveira SRM, Santos I (2006) Gerência do processo de trabalho em enfermagem: liderança da enfermeira em unidades hospitalares. Texto Contexto Enfermagem 15:393-400.

Chaves LDP, Massaro M (2009) Produção científica sobre gerenciamento em enfermagem hospitalar: uma pesquisa bibliográfica. Cogitare Enfermagem 14:150-158.

Ciampone MH (2012) O processo de construção do perfil de competências gerenciais para enfermeiros coordenadores de área hospitalar. Revista Escola de Enfermagem da Universidade de São Paulo 46:3.

Costa RP (2009) Gerenciamento do cuidado de enfermagem: a experiência de um hospital de ensino. Dissertação (mestrado) - UFRJ/ EEAN/ Programa de Pós-graduação em Enfermagem.

Erdmann AL (2001) Administração do processo de trabalho e da assistência de enfermagem: In: SANTOS, I. et al. Enfermagem fundamental: realidade, questões, soluções. São Paulo: Atheneu.

Erdmann AL (2013) Prazer e sofrimento no exercício gerencial do enfermeiro no contexto hospitalar. Escola Anna Nery 1:97-103.

Fernandes AT (2000) As Infecções Hospitalares e suas interfaces na área da saúde, São Paulo: Atheneu.

Formiga JMM, Germano RM (2005) Por Dentro da História: o ensino de Administração em Enfermagem. Revista Brasileira de Enfermagem 2:222-226

Hausmann M, Peduzzi M (2009) Articulação entre as dimensões gerencial e assistencial do processo de trabalho do enfermeiro. Texto Contexto Enfermagem 2:258-265.

Jorge MSB, Freitas CHA, Nobrega, MFB, Queiroz, VO (2007) Gerenciamento em enfermagem: um olhar crítico sobre o conhecimento produzido em periódicos brasileiros (2000 - 2004) Revista Brasileira de Enfermagem 60:81- 86.

Kurgant P (1991) As teorias de administração e os serviços de enfermagem. Administração de enfermagem. São Paulo: EPU.

Manenti SA (2008) O processo de construção do perfil de competências gerenciais para enfermeiros coordenadores de área hospitalar. Dissertação (mestrado) da Escola de Enfermagem da Universidade de São Paulo.

Maximiano ACA (2000) Teoria Geral da Administração: da escola científica à competitividade na economia globalizada. 2.ed. São Paulo: Atlas. 
Nascimento SM (2013) As funções gerenciais do enfermeiro no cotidiano da assistência hospitalar. (Monografia) Rio de Janeiro, UNIRIO, Enfermagem. Disponível em: <http://www2.unirio.br/unirio/ccbs/ppgenf/arquivos/dissertacoes-arquivo/dissertacoes2013/simone-martins-nascimento> Acesso em 20 nov 2015.

Peduzzi M, Hausmann MA (2005) enfermagem como prática heterogênea que busca ressignificar as interfaces entre seus diferentes agentes e objetos de trabalho. Livro-Temas do 56 Congresso Brasileiro de Enfermagem; Enfermagem hoje: coragem de experimentar
muitos
modos
de ser.
Out 24-29;
Brasília
(DF):
ABEn.
Disponível
em:

<www.bstorm.com.br/enfermagem/palestrantes/Marina\%20Peduzzi.php> Acesso em 02 fev 2016.

Peres AM, Ciampone MHT (2006) Gerência e competências gerais do enfermeiro. Texto Contexto Enfermagem 15:492-499.

Pompeu B, Sanches VF, Silvino CZR (2006) Processo de trabalho do gerente de enfermagem em unidade hospitalar - uma visão dos enfermeiros. Escola Anna Nery 10:214-220.

Santos SR (2007) Administração aplicada à enfermagem. 3.ed. João Pessoa: Ideia.

Soares E, Souza F M (2006) A visão administrativa do enfermeiro no macrossistema hospitalar: um estudo reflexivo Revista Brasileira de Enfermagem 59:620-625.

Shinyashiki GT, Trevizan MA, Mendes IAC (2003) Sobre a criação e a gestão do conhecimento organizacional. Revista Latinoamericana Enfermagem 11:499-506.

Trevizan MA (1988) Enfermagem hospitalar: administração e burocracia.Brasília (DF): Editora Universidade de Brasília.

Willig MH (2004) Cuidar/gerenciar: possibilidades de convergência no discurso coletivo das enfermeiras. Curitiba. Dissertação (Mestrado) Setor de Ciências da Saúde, Universidade Federal do Paraná. Disponivel em: <http://www.ppgenf.ufpr.br/Disserta\%C3\%A7\%C3\%A3oWillig.pdf> Acesso em 02 Fev 2016. 